\title{
Recovery of CYP3A Phenotype after Kidney Transplantation
}

\author{
Kristine Hole, Elisabet Størset, Ane Olastuen, Tore Haslemo, Grete Birkeland Kro, \\ Karsten Midtvedt, Anders Åsberg, and Espen Molden
}

Center for Psychopharmacology, Diakonhjemmet Hospital (K.H., T.H., E.M.), Department of Transplantation Medicine (E.S., K.M., A. A.) and Department of Microbiology (G.B.K.), Oslo University Hospital Rikshospitalet, and Department of Pharmaceutical Biosciences, School of Pharmacy, University of Oslo (A.O., A.A., E.M.), Oslo, Norway

Received August 10, 2017; accepted September 15, 2017

\begin{abstract}
End-stage renal disease impairs drug metabolism via cytochrome P450 CYP3A; however, it is unclear whether CYP3A activity recovers after kidney transplantation. Therefore, the aim of this study was to evaluate the change in CYP3A activity measured as $4 \beta$-hydroxycholesterol $(4 \beta \mathrm{OHC})$ concentration after kidney transplantation. In total, data from 58 renal transplant recipients with 550 prospective $4 \beta O H C$ measurements were included in the study. One sample per patient was collected before transplantation, and 2-12 samples per patient were collected 1-82 days after transplantation. The measured
\end{abstract}

\section{Introduction}

End-stage renal disease (ESRD) impairs not only renal drug clearance but also nonrenal clearance via impairment of cytochrome P450 (P450) enzymes and drug transport proteins (Ladda and Goralski, 2016). Several P450 enzymes display reduced activity in ESRD patients (Ladda and Goralski, 2016); the mechanism behind this occurrence is not fully understood, but it might be related to direct inhibition of $\mathrm{P} 450$ metabolism or reduced protein expression caused by uremic toxins (Guevin et al., 2002; Barnes et al., 2014).

The CYP3A subfamily is involved in the metabolism of $30 \%$ of clinically used drugs, and CYP3A4 and CYP3A5 are the most relevant enzymes (Zanger and Schwab, 2013). Both enzymes display genetic polymorphisms, but the functional relevance is most evident for CYP3A5, where the $C Y P 3 A 5 * 3$ variant allele - being the most frequent allele in most populations - encodes for a nonfunctional CYP3A5 enzyme (Kuehl et al., 2001). For CYP3A4, the CYP3A4*22 variant allele is related to reduced enzyme activity (Wang et al., 2011) and has been associated with an approximately $30 \%$ reduced tacrolimus dose requirement (Elens et al., 2011); however, the general relevance of CYP3A4*22 on CYP3A phenotype is unclear.

Because of the extensive and mainly nongenetic interindividual variability in CYP3A enzyme activity, phenotyping is likely to be more clinically useful than genotyping for dose individualization. Midazolam is considered the gold standard probe drug for measuring CYP3A4 phenotype, but endogenous phenotype markers have the advantage of not needing probe drug administration. $4 \beta$-Hydroxycholesterol $(4 \beta \mathrm{OHC})$ is metabolized from cholesterol by CYP3A4 and CYP3A5

This study was supported by a grant from the South-Eastern Norway Regional Health Authority.

https://doi.org/10.1124/dmd.117.078030. pretransplant $4 \beta \mathrm{OHC}$ concentrations ranged by $>7$-fold, with a median value of $22.8 \mathrm{ng} / \mathrm{ml}$. Linear mixed-model analysis identified a $0.16-\mathrm{ng} / \mathrm{ml}$ increase in $4 \beta O H C$ concentration per day after transplantation $(P<0.001)$, indicating a regain in CYP3A activity. Increasing estimated glomerular filtration rate after transplantation was associated with increasing $4 \beta O H C$ concentration $(P<0.001)$, supporting that CYP3A activity increases with recovering uremia. In conclusion, this study indicates that CYP3A activity is regained subsequent to kidney transplantation.

ABBREVIATIONS: $4 \beta \mathrm{OHC}, 4 \beta$-hydroxycholesterol; eGFR, estimated glomerular filtration rate; ESRD, end-stage renal disease; LLOQ, lower limit of quantification; P450, cytochrome P450. 
TABLE 1

Clinical and demographic patient characteristics

Data are expressed as numbers or median (range).

\begin{tabular}{lccc}
\hline & Patients with $C Y P 3 A 4 * 1 / * 22$ & Patients with $C Y P 3 A 4 * 1 / * 1$ and $C Y P 3 A 5 * 3 / * 3$ & Patients with $C Y P 3 A 5 * 1 / * 3$ \\
\hline No. of patients & 5 & 41 & 12 \\
Sex (M/F) & $4 / 1$ & $27 / 14$ & $8 / 4$ \\
Age, yr & $63(47-66)$ & $54(24-76)$ & $61(30-74)$ \\
Body weight before transplantation, kg & $89(76-104)$ & $76(58-116)$ & $40 / 1$ \\
Ethnicity (white/other) & $5 / 0$ & $12 / 29$ & $3-118)$ \\
Donor (living/deceased) & $1 / 4$ & $37 / 3 / 1$ & $3 / 3$ \\
Previous transplantations (0/1/2) & $5 / 0 / 0$ & $19 / 9 / 13$ & $12 / 0 / 0$ \\
Pretransplant dialysis (HD/PD/none) & $2 / 1 / 2$ & $7 / 2 / 3$ \\
\hline
\end{tabular}

$\mathrm{HD}$, hemodialysis; PD, peritoneal dialysis.

tacrolimus, mycophenolate mofetil, and oral prednisolone (Storset et al., 2015). Induction therapy consisted of $20 \mathrm{mg}$ of basiliximab on day 0 and 4, and i.v. methylprednisolone on day 0 . None of the included patients used CYP3A inducers or inhibitors during the study period, except for corticosteroids. Acute rejection episodes and concurrent methylprednisolone treatment were registered. The study was approved by the Regional Committee for Medical Research Ethics. All participants gave written, informed consent.

Genotype Analyses. Analyses of $C Y P 3 A 4 * 22$ (rs35599367) and $C Y P 3 A 5 * 3$ (rs776746) variant alleles were performed by real-time polymerase chain reaction and melt curve analysis with hybridization probes on the LightCycler 480 instrument (Roche Applied Science, Penzberg, Germany).

4及OHC Analyses. Plasma concentrations of $4 \beta \mathrm{OHC}$ were determined by a previously described ultraperformance liquid chromatography tandem mass spectrometry method using atmospheric pressure chemical ionization (Gjestad et al., 2016), with an added filtration step (Størset et al., 2017). A quality-control sample produced at the time of the oldest samples (January 2014) was included in each run to ensure stability during storage. Duplicate measurements were performed for each sample, and mean values of duplicates were used for statistical analyses. The lower limit of quantification (LLOQ) was $10 \mathrm{ng} / \mathrm{ml}$, and $4 \beta \mathrm{OHC}$ measurements below LLOQ were excluded from statistical analysis. Intraday and interday precision for the method was $<8 \%$ at $10 \mathrm{ng} / \mathrm{ml}$ and $<4 \%$ at $644 \mathrm{ng} / \mathrm{ml}(n=6)$, whereas the corresponding intraday and interday accuracies were $<15 \%$ and $<2 \%$, respectively $(n=6)$.

Creatinine Analyses. Plasma creatinine was analyzed in fresh samples on the COBAS 8000 platform using the Roche CREP2 kit, a colorimetric based method (no. 05168589190; Roche, Basel Switzerland). The intrapatient and interpatient coefficients of variation were $5.3 \%$ and $14.2 \%$, respectively.

Endpoints and Statistical Analyses. Kruskal-Wallis and Mann-Whitney $U$ tests were used for comparison of pretransplantation $4 \beta \mathrm{OHC}$ concentrations between subgroups. Correlations were evaluated using Spearman's signed rank test. Linear mixed-modeling with random intercept and random slope was used to evaluate the effects of covariates on variation in $4 \beta \mathrm{OHC}$ concentration. An unstructured covariance type was used, and calculation of estimates was based on restricted maximum likelihoods. Evaluated fixed effects included $C Y P 3 A 4$ and CYP3A5 genotypes, days since transplantation, estimated glomerular filtration rate (eGFR) calculated by the Cockcroft-Gault-formula (Cockcroft and Gault, 1976), body weight, sex, age, whether the patient had undergone dialysis before transplantation (independent of previous transplantations), and whether the transplant originated from a living or deceased donor. Two separate mixedmodel analyses were performed: one including samples from pretransplantation and post-transplantation, where body weight was included as a covariate but not eGFR, and one including samples only from post-transplantation, where eGFR was included as a covariate but not body weight. Since body weight is incorporated in the eGFR, we did not use both covariates in the same analyses. The final mixed-models were chosen by Akaike's information criterion, and only statistically significant covariates were included.

The impact of genotype on change in $4 \beta \mathrm{OHC}$ concentration over time was assessed by comparing the slope of change in $4 \beta \mathrm{OHC}$ concentration between genotype subgroups. Statistical significance was considered as $P<0.05$. Statistical analyses were performed using the IBM SPSS Statistics for Windows, version 21.0 (IBM Corp., Armonk, NY). SPSS and GraphPad Prism for Windows, version 6.01 (GraphPad Software, La Jolla, CA), were used for graphical presentations.

\section{Results}

Patient Characteristics. One patient was a carrier of both $C Y P 3 A 4 * 22$ and $C Y P 3 A 5 * 1$ alleles and was excluded from the study. Clinical and demographic characteristics of the 58 remaining patients are listed in Table 1 . Thirty-nine patients were male $(67 \%)$, and the median
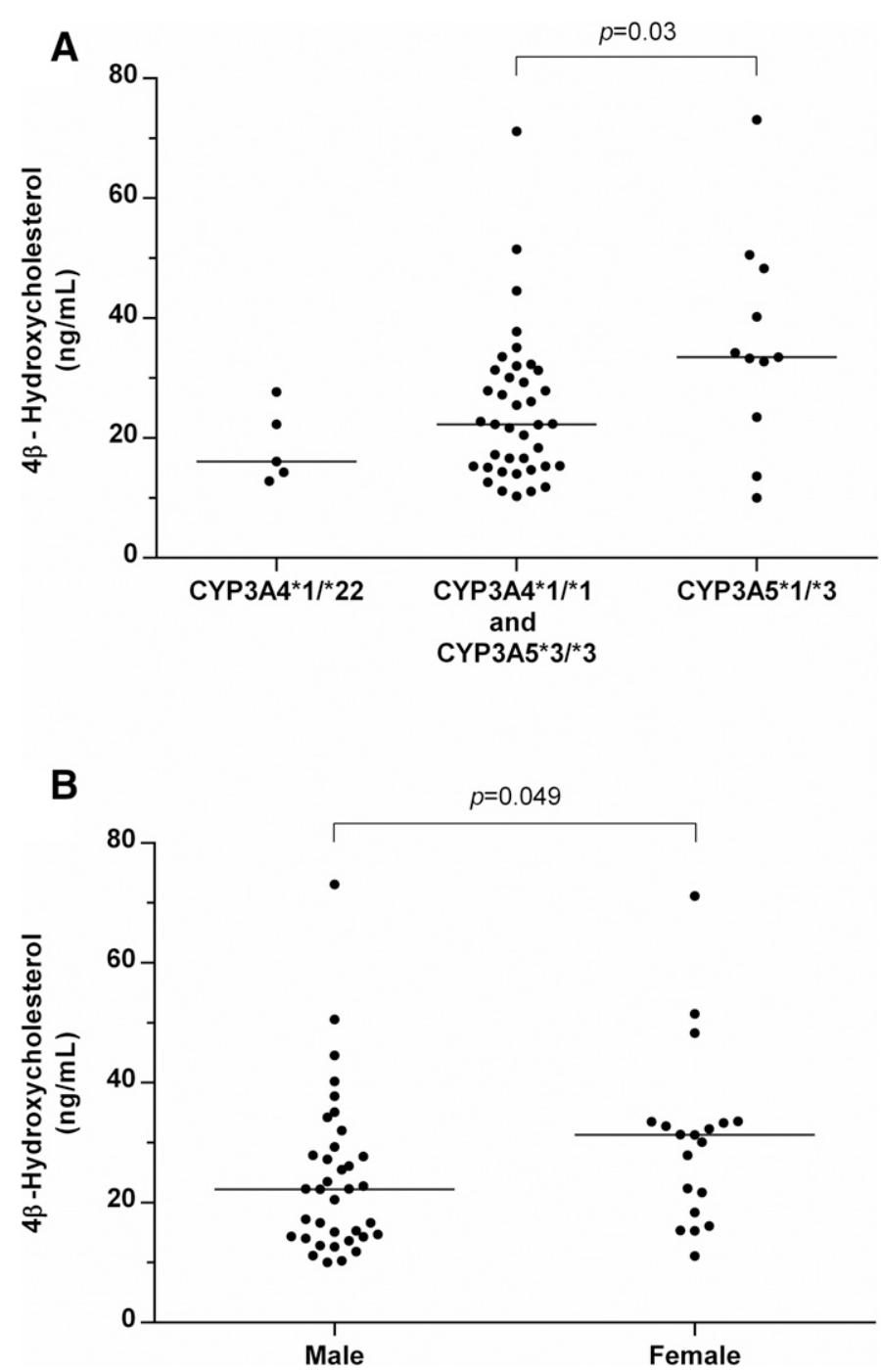

Fig. 1. Pretransplantation $4 \beta \mathrm{OHC}$ concentrations in (A) $C Y P 3 A 4 * 22$ carriers $(n=5), C Y P 3 A 4 * 1 / * 1$ and $C Y P 3 A 5 * 3 / * 3$ homozygotes $(n=39)$, and $C Y P 3 A 5 * 1$ carriers $(n=11)$, and (B) males $(n=36)$ and females $(n=19)$. Medians are expressed as solid lines, and $P$ values are derived from Mann-Whitney $U$ tests. 

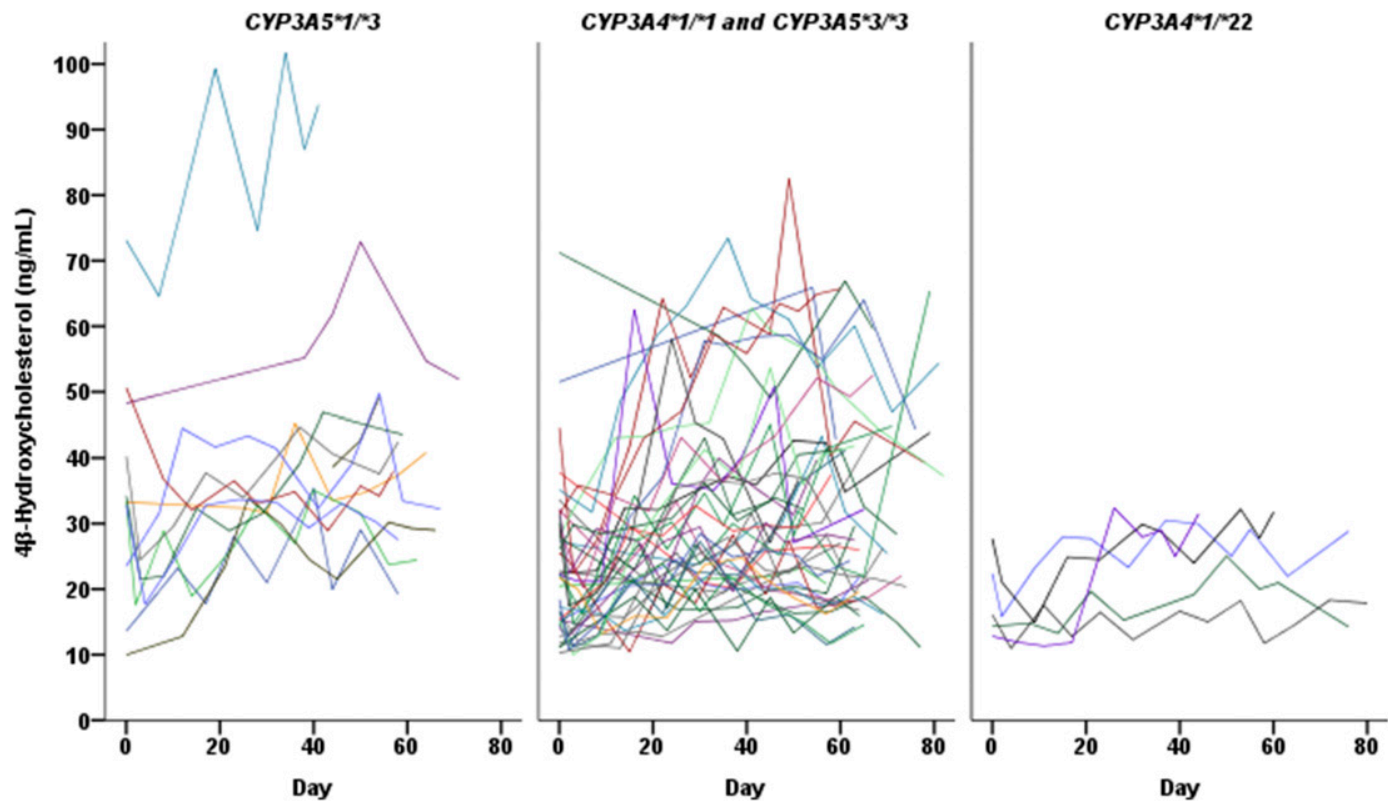

Fig. 2. Measured $4 \beta \mathrm{OHC}$ concentrations in all patients according to days after transplantation and stratified by $C Y P 3 A 4$ and $C Y P 3 A 5$ genotypes.

age was 56 years (range 24-76). This was the first kidney transplantation for 54 of the patients $(93 \%)$. Forty patients $(69 \%)$ had undergone dialysis treatment before transplantation, of which one patient was receiving a retransplant. Regarding genotype distributions in the population, five patients $(9 \%)$ had the $C Y P 3 A 4 * 1 / * 22$ genotype and 12 patients $(21 \%)$ had the $C Y P 3 A 5 * 1 / * 3$ genotype. The remaining 41 patients $(71 \%)$ were $C Y P 3 A 4 * 1 / * 1$ and $C Y P 3 A 5 * 3 / * 3$ homozygotes. Three of the patients carrying the $C Y P 3 A 5 * 1$ allele were of non-Caucasian.

Pretransplantation 4及OHC Concentration. One $4 \beta \mathrm{OHC}$ measurement was available from the period immediately before transplantation (1-10 days) for all but three patients; two patients lacked measurements owing to a shortage of plasma, and one measurement was excluded because of level below LLOQ. Pretransplant $4 \beta \mathrm{OHC}$ concentrations of the remaining 55 patients ranged to $>7$-fold $(10.0-73.1 \mathrm{ng} / \mathrm{ml})$, with a median value of $22.8 \mathrm{ng} / \mathrm{ml}$. The median pretransplantation $4 \beta \mathrm{OHC}$ concentration in $C Y P 3 A 4 * 22$ carriers was $16.1 \mathrm{ng} / \mathrm{ml}$ (range, $12.8-27.7 \mathrm{ng} / \mathrm{ml}, n=5$ ); in combined $C Y P 3 A 4^{*} 1 / * 1$ and $C Y P 3 A 5 * 3 / 3$ homozygotes, it was $22.3 \mathrm{ng} / \mathrm{ml}(10.3-71.2 \mathrm{ng} / \mathrm{ml}$, $n=39)$, and in $C Y P 3 A 5 * 1$ carriers, it was $33.5 \mathrm{ng} / \mathrm{ml}(10.0-73.1 \mathrm{ng} / \mathrm{ml}$, $n=11$ ) (Kruskal-Wallis $P=0.04$ ). The Mann-Whitney $U$ test revealed a significant difference in $4 \beta \mathrm{OHC}$ concentration between $C Y P 3 A 5^{*} 1$ carriers and patients with combined $C Y P 3 A 4 * 1 / * 1$ and $C Y P 3 A 5 * 3 / * 3$ genotypes $(P=0.03)$ but not between $C Y P 3 A 4 * 22$ carriers and patients with combined CYP3A $4 * 1 / * 1$ and CYP3A $5 * 3 / * 3$ genotypes $(P=0.3)$ (Fig. 1A). As shown in Fig. 1B, female patients had a median $4 \beta \mathrm{OHC}$ concentration of $31.3 \mathrm{ng} / \mathrm{ml}(11.1-71.2 \mathrm{ng} / \mathrm{ml})$ compared with $22.3 \mathrm{ng} / \mathrm{ml}$ in male patients $(10.0-73.1 \mathrm{ng} / \mathrm{ml}$ ) (Mann-Whitney $P=0.049)$. Pretransplantation $4 \beta \mathrm{OHC}$ concentration was not different between dialysis and nondialysis patients (Mann-Whitney $P=0.5$ ). Pretransplant body weight correlated with $4 \beta \mathrm{OHC}$ concentration (Spearman's $r=-0.58, P<0.001$ ).

Change in $4 \beta O H C$ Concentration after Transplantation. A median of nine $4 \beta \mathrm{OHC}$ measurements per patient (range, 2-12) were available from the post-transplantation period (1-82 days). Nine posttransplant $4 \beta \mathrm{OHC}$ measurements were below LLOQ and were not included in the statistical analysis. In total, 550 pretransplantation and post-transplantation $4 \beta \mathrm{OHC}$ measurements from 58 patients were included in the study (Fig. 2). Thirty-nine body weight measurements and 27 creatinine concentration measurements were missing during follow-up after transplantation.

As shown in Fig. 3, correlation between plasma creatinine and $4 \beta \mathrm{OHC}$ concentrations from week 1 post-transplantation was borderline significant (Spearman's $r=-0.36, P=0.053, n=30$ ). Linear mixedmodeling analysis, including both pretransplantation and posttransplantation samples, identified "days since transplantation," body weight, and $C Y P 3 A 5$ genotype as significant covariates with impact on $4 \beta \mathrm{OHC}$ concentration (Table 2$)$. The final model predicted an increase of $0.16 \mathrm{ng} / \mathrm{ml}$ in $4 \beta \mathrm{OHC}$ per day after transplantation $(P<0.001)$, which corresponds to a $13.1 \mathrm{ng} / \mathrm{ml}$ increase in $4 \beta \mathrm{OHC}$ concentration from before transplantation to day 82 after transplantation, or a $46 \%$ increase for a 70-kg person. An increase in body weight of $1 \mathrm{~kg}$ predicted a $0.4 \mathrm{ng} / \mathrm{ml}$ reduction in $4 \beta \mathrm{OHC}$ concentration $(P<0.001)$, which corresponds to a pretransplantation $4 \beta \mathrm{OHC}$ concentration of $33 \mathrm{ng} / \mathrm{ml}$ for a $60-\mathrm{kg}$ patient and $16 \mathrm{ng} / \mathrm{ml}$ for a $100-\mathrm{kg}$ patient who did not express

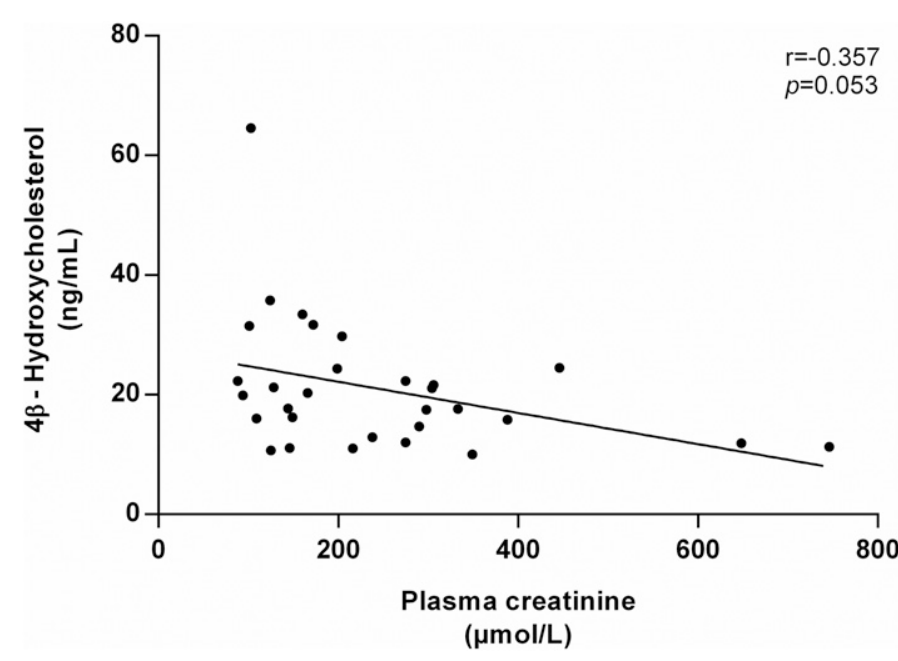

Fig. 3. Correlation between $4 \beta \mathrm{OHC}$ concentration and creatinine concentration 1 week after transplantation $(n=30) . P$ and $r$ values are estimated from Spearman's test. Linear trend line is added for visual purposes. 
TABLE 2

Linear mixed-model estimates for predictors of $4 \beta \mathrm{OHC}$ concentration (nanograms per milliliter) including pretransplantation and post-transplantation samples

\begin{tabular}{|c|c|c|c|c|}
\hline \multirow[b]{2}{*}{ Variables } & \multicolumn{4}{|c|}{ 95\% Confidence Interval } \\
\hline & Estimate & Lower Bound & Upper Bound & $P$ Value \\
\hline Intercept & 59.58 & 46.78 & 72.38 & $<0.001$ \\
\hline Time since transplantation, days & +0.16 & +0.11 & +0.22 & $<0.001$ \\
\hline Body weight, kg & -0.44 & -0.59 & -0.29 & $<0.001$ \\
\hline$C Y P 3 A 5 * 1$ carrier $^{a}$ & +7.78 & +1.23 & +14.33 & 0.02 \\
\hline
\end{tabular}

CYP3A5. Carrying the $C Y P 3 A 5 * 1$ allele indicated a $7.8 \mathrm{ng} / \mathrm{ml}$ higher $4 \beta \mathrm{OHC}$ level than being homozygous for $C Y P 3 A 5 * 3 / * 3(P=0.02)$. Being a carrier of the $C Y P 3 A 4 * 22$ allele did not have a significant impact on $4 \beta \mathrm{OHC}$ levels $(P=0.5)$, nor did sex, age, pretransplant dialysis status, or whether the transplanted kidney originated from a living or deceased donor $(P>0.2)$. The slope of change in $4 \beta \mathrm{OHC}$ concentration according to days after transplantation was not significantly different between the genotype subgroups $(P>0.5)$. When all samples from patients after a rejection episode and concurrent methylprednisolone treatment were excluded, the results of the mixed-model analysis were essentially the same (no differences in significance levels of the tested variables; results not shown). A linear mixed-model analysis based solely on post-transplantation samples further identified an association between $4 \beta \mathrm{OHC}$ concentration and eGFR (Table 3). A $10 \mathrm{ml} / \mathrm{min}$ increase in eGFR was associated with a $1.0 \mathrm{ng} / \mathrm{ml}$ increase in $4 \beta \mathrm{OHC}$ levels $(P<0.001)$.

\section{Discussion}

Our study of 58 kidney transplant recipients showed a gradual increase in CYP3A activity from immediately before to 82 days after kidney transplantation, suggesting that CYP3A impairment resulting from ESRD is recovered subsequent to transplantation. Furthermore, a post-transplantation increase in $4 \beta \mathrm{OHC}$ concentration was associated with increasing eGFR, supporting that uremia or uremic toxins impair CYP3A activity. The degree of increase in CYP3A activity was not statistically associated with $C Y P 3 A 4$ or $C Y P 3 A 5$ genotypes.

The gradual increase in $4 \beta \mathrm{OHC}$ concentration with increasing time after transplantation coincides with findings in Japanese kidney transplant recipients, in which a $30 \%-50 \%$ increase in $4 \beta \mathrm{OHC}$ concentration was found on days 90 and 180 after transplantation compared with pretransplant $4 \beta \mathrm{OHC}$ concentration (Suzuki et al., 2013, 2015). Furthermore, in vitro studies of rat hepatocytes incubated with serum from chronic renal failure patients reported a reduction in CYP3A activity and enzyme expression before, but not after, transplantation (Michaud et al., 2005). Clinical implications could be that dose reductions of CYP3A-metabolized drugs in ESRD patients may prevent overdosing and concentration-dependent side effects and, correspondingly, that a post-transplantation dose increase in CYP3A drugs may prevent therapeutic failure. It should be mentioned, however, that one study reported a decreased clearance of the CYP3A substrate midazolam 1-12 months after transplantation compared with 7 days after transplantation (de Jonge et al., 2015). Although midazolam is considered a gold standard CYP3A probe drug, it is also highly bound to plasma proteins (Kirwan et al., 2010). Albumin levels are reported to be reduced in patients with chronic kidney disease and after recent surgery (Meijers et al., 2008; Hubner et al., 2016) and increase with time after transplantation (Størset et al., 2014). Thus, it is possible that the reported decreasing midazolam plasma clearance reflects mainly increasing protein binding rather than decreasing CYP3A activity. Nevertheless, further studies are needed to elucidate the change in CYP3A activity after kidney transplantation and the potential clinical relevance of such a change.

The median value of pretransplantation $4 \beta \mathrm{OHC}$ concentration in the present population was $22.8 \mathrm{ng} / \mathrm{ml}$, which is approximately $10 \%$ lower than the reported median concentration in a Norwegian patient population of psychiatric patients (Hole et al., 2017) and approximately 15\%-25\% lower than mean concentrations in healthy Scandinavian volunteers (Bodin et al., 2001; Diczfalusy et al., 2008). This finding supports that CYP3A activity is impaired in ESRD patients. The mechanism through which ESRD impairs CYP3A activity is not fully elucidated, but it is considered to involve uremic toxins (Ladda and Goralski, 2016). Possible mechanisms include direct enzymatic inhibition and/or reduced P450 gene expression by uremic toxins (Barnes et al., 2014; Ladda and Goralski, 2016). Suzuki et al. (2014) reported a negative correlation of plasma indoxyl sulfate with $4 \beta \mathrm{OHC}$ concentration in stable kidney transplant recipients, indicating that a posttransplant decline in uremic toxin was linked to regain of CYP3A activity. This coincides with our findings that a post-transplantation increase in eGFR was associated with an increase in $4 \beta \mathrm{OHC}$ concentration.

We observed a significant impact of $C Y P 3 A 5$, but not $C Y P 3 A 4$, genotype on pretransplant $4 \beta \mathrm{OHC}$ concentration. There were only five

TABLE 3

Linear mixed-model estimates for predictors of $4 \beta \mathrm{OHC}$ concentration (nanograms per milliliter) including solely posttransplantation samples

\begin{tabular}{|c|c|c|c|c|}
\hline \multirow[b]{2}{*}{ Variables } & \multicolumn{4}{|c|}{ 95\% Confidence Interval } \\
\hline & Estimate & Lower Bound & Upper Bound & $P$ value \\
\hline Intercept & 15.64 & 11.25 & 20.03 & $<0.001$ \\
\hline Time since transplantation, days & +0.18 & +0.12 & +0.24 & $<0.001$ \\
\hline Estimated glomerular filtration rate, $\mathrm{ml} / \mathrm{min}$ & +0.10 & +0.05 & +0.16 & $<0.001$ \\
\hline$C Y P 3 A 5^{*} 1$ carrier $^{a}$ & +10.43 & +3.65 & +17.20 & 0.003 \\
\hline
\end{tabular}

${ }^{a}$ Versus noncarrier. 
$C Y P 3 A 4 * 22$ carriers, which may explain why the $4 \beta O H C$ concentration was not significantly lower in this group compared with the other genotype groups. It is also possible that nongenetic factors, such as inflammation and uremic toxins, mask the effects of $C Y P 3 A 4$ genotype on CYP3A phenotype in this population (Morgan, 1997; Suzuki et al., 2014). Suzuki et al. (2015) reported identical pretransplantation $4 \beta \mathrm{OHC}$ levels in $C Y P 3 A 5 * 1$ carriers and noncarriers, with a mean concentration of $38 \mathrm{ng} / \mathrm{ml}$. They further reported a post-transplantation increase in $4 \beta \mathrm{OHC}$ concentration only among $C Y P 3 A 5^{*} 1$ carriers, and not among CYP3A5*3/*3 homozygotes (Suzuki et al., 2015). We found no difference in the post-transplantation increase in $4 \beta \mathrm{OHC}$ concentration when comparing $C Y P 3 A 4 * 22$ carriers, $C Y P 3 A 4 * 1 / * 1$ and $C Y P 3 A 5 * 3 / * 3$ homozygotes, and $C Y P 3 A 5 * 1$ carriers, indicating a recovery of CYP3A activity independent of genotype. The inconsistent findings regarding impact of $C Y P 3 A 4 / 5$ genotype on metabolizing phenotype both before and after kidney transplantation might be related to ethnic differences, but this this speculation needs to be investigated in further studies.

In this study, we used $4 \beta \mathrm{OHC}$ concentrations as a measure of in vivo CYP3A activity without adjusting for total cholesterol levels. Total cholesterol has only minor impact on the variation in $4 \beta \mathrm{OHC}$ concentration (Diczfalusy et al., 2008), except for in statin-treated patients (Bjorkhem-Bergman et al., 2016). None of the patients included in our study received statins. Thus, it is not expected that using the $4 \beta \mathrm{OHC}$-cholesterol ratio would have led to different conclusions. The elimination half-life of $4 \beta \mathrm{OHC}$ is considered to be between 3 and 17 days (Bodin et al., 2002; Diczfalusy et al., 2009; Ngaimisi et al., 2014), which is a limitation when studying changes in CYP3A activity over short periods; however, the fact that use of a CYP3A inducer for a week doubles $4 \beta \mathrm{OHC}$ concentration indicates that this biomarker rapidly captures increased enzyme activity (Marschall et al., 2005; Wide et al., 2008). We are therefore confident that $4 \beta \mathrm{OHC}$ can reflect recovery in CYP3A activity within the time span of our study.

Studying the dynamic changes early after kidney transplantation is complex, and several factors were not accounted for in our analysis, such as delayed graft function, albumin levels, and corticosteroid doses. All patients received methylprednisolone on the day of transplantation and prednisolone in the immunosuppressive regimen. CYP3A induction by corticosteroids is reported in the literature, most potently by dexamethasone, but also by prednisolone and methylprednisolone (Matoulkova et al., 2014). Clinical observations of increasing tacrolimus concentrations concurring with tapering of corticosteroid dosing has been interpreted as indirect evidence that corticosteroid induction of CYP3A and P-glycoprotein is of clinical relevance; however, we showed that CYP3A activity measured as $4 \beta \mathrm{OHC}$ did not account for the increasing tacrolimus concentration with time after kidney transplantation (Størset et al., 2017). The conclusions regarding corticosteroid CYP3A induction are conflicting, and the clinical evidence is limited (Matoulkova et al., 2014). Therefore, we do not suspect that the post-transplant increase in CYP3A activity is due to corticosteroid P450 induction, but both oral and i.v. corticosteroids given after transplantation may still have been an interfering factor on $4 \beta \mathrm{OHC}$ levels that were not completely accounted for in our study. In future studies, it will be important to account for interfering factors, such as corticosteroid use, on post-transplant regain of CYP3A phenotype.

The P450 enzymes, including CYP3A isoforms, are known to be expressed in kidneys (Aleksa et al., 2005). The increased metabolic activity after transplantation might therefore, in theory, reflect higher renal CYP3A activity in the donor kidney than in the impaired kidney. CYP3A5 expression has been shown to be lower in renal transplant patients with calcine urine-induced nephrotoxicity compared with controls, which could support that metabolic activity declines during renal failure (Joy et al., 2007). Aleksa et al., however, have reported that total expression of $\mathrm{P} 450$ enzymes in the kidneys is $80 \%-90 \%$ lower than in the liver (Aleksa et al., 2005). Overall, we therefore consider it likely that the increase in $4 \beta \mathrm{OHC}$ level after transplantation reflects mainly a gradual regain of CYP3A metabolism in the liver/intestine, but it is possible that higher metabolic activity in the donor versus the failing kidney may have contributed to the observed increase in $4 \beta \mathrm{OHC}$ concentration. Regarding causality behind the post-transplant increase in $4 \beta \mathrm{OHC}$ concentrations, it is necessary with further investigation to clarify the possible mechanisms behind the suppression of CYP3A phenotype in ESRD patients. Another limitation in our study is the low number of $C Y P 3 A 4 * 22$ carriers. Since the $C Y P 3 A 4 * 22$ allele codes for a reduced function enzyme, and patients are rarely homozygous, a larger number of patients would probably be needed to find significant impact on CYP3A phenotype. Furthermore, there were no $C Y P 3 A 5^{*} 1 / * 1$ homozygotes, so we could not investigate whether there was a stepwise increase in $4 \beta \mathrm{OHC}$ concentration according to number of $C Y P 3 A 5^{*} 1$ alleles. The main strength of our study is the large number of samples from the early post-transplant period, which allowed us to investigate intraindividual and interindividual changes in $4 \beta \mathrm{OHC}$ concentration after transplantation. The study would have been strengthened by investigating the clinical effect of change in $4 \beta \mathrm{OHC}$ concentration on clearance of CYP3A-metabolized drugs. We have previously reported that $4 \beta \mathrm{OHC}$ concentration did not improve tacrolimus dose predictions (Størset et al., 2017). It would be interesting to determine whether the $4 \beta \mathrm{OHC}$ concentration in ESRD patients and early after transplantation is associated with the clearance of other CYP3A drugs with less complex pharmacokinetic profiles than tacrolimus.

In conclusion, we found that CYP3A activity increased after kidney transplantation, indicating a regain of enzyme activity impaired by ESRD. Clinically, this implicates that dosing of CYP3A-metabolized drugs may need to be reduced in patients with ESRD and increased after kidney transplantation.

\section{Acknowledgments}

We thank Jukka Corander at the Department of Biostatistics, University of Oslo, for valuable input on the statistical analyses.

\section{Authorship Contributions}

Participated in research design: Hole, Størset, Olastuen, Midtvedt, Åsberg, Molden.

Contributed new reagents or analytic tools: Hole, Størset, Olastuen, Kro, Midtvedt, Åsberg, Molden.

Performed data analysis: Hole, Haslemo.

Wrote or contributed to the writing of the manuscript: Hole, Størset, Olastuen, Haslemo, Kro, Midtvedt, Åsberg, Molden.

\section{References}

Aleksa K, Matsell D, Krausz K, Gelboin H, Ito S, and Koren G (2005) Cytochrome P450 3A and 2B6 in the developing kidney: implications for ifosfamide nephrotoxicity. Pediatr Nephrol 20: $872-885$.

Barnes KJ, Rowland A, Polasek TM, and Miners JO (2014) Inhibition of human drug-metabolising cytochrome P450 and UDP-glucuronosyltransferase enzyme activities in vitro by uremic toxins. Eur J Clin Pharmacol 70:1097-1106.

Björkhem-Bergman L, Nylén H, Eriksson M, Parini P, and Diczfalusy U (2016) Effect of statin treatment on plasma $4 \beta$-hydroxycholesterol concentrations. Basic Clin Pharmacol Toxicol 118: 499-502.

Bodin K, Andersson U, Rystedt E, Ellis E, Norlin M, Pikuleva I, Eggertsen G, Björkhem I, and Diczfalusy U (2002) Metabolism of 4 beta -hydroxycholesterol in humans. J Biol Chem 277: 31534-31540.

Bodin K, Bretillon L, Aden Y, Bertilsson L, Broomé U, Einarsson C, and Diczfalusy U (2001) Antiepileptic drugs increase plasma levels of 4beta-hydroxycholesterol in humans: evidence for involvement of cytochrome p450 3A4. J Biol Chem 276:38685-38689.

Cockcroft DW and Gault MH (1976) Prediction of creatinine clearance from serum creatinine. Nephron 16:31-41.

de Jonge H, Vanhove T, de Loor H, Verbeke K, and Kuypers DRJ (2015) Progressive decline in tacrolimus clearance after renal transplantation is partially explained by decreasing CYP3A4 activity and increasing haematocrit. Br J Clin Pharmacol 80:548-559. 
Diczfalusy U, Kanebratt KP, Bredberg E, Andersson TB, Böttiger Y, and Bertilsson L (2009) 4beta-hydroxycholesterol as an endogenous marker for CYP3A4/5 activity. Stability and half-life of elimination after induction with rifampicin. Br J Clin Pharmacol 67:38-43.

Diczfalusy U, Miura J, Roh HK, Mirghani RA, Sayi J, Larsson H, Bodin KG, Allqvist A, Jande M, Kim JW, et al. (2008) 4Beta-hydroxycholesterol is a new endogenous CYP3A marker: relationship to CYP3A5 genotype, quinine 3-hydroxylation and sex in Koreans, Swedes and Tanzanians. Pharmacogenet Genomics 18:201-208.

Dowling TC, Briglia AE, Fink JC, Hanes DS, Light PD, Stackiewicz L, Karyekar CS, Eddington ND, Weir MR, and Henrich WL (2003) Characterization of hepatic cytochrome p4503A activity in patients with end-stage renal disease. Clin Pharmacol Ther 73:427-434.

Elens L, Bouamar R, Hesselink DA, Haufroid V, van der Heiden IP, van Gelder T, and van Schaik RH (2011) A new functional CYP3A4 intron 6 polymorphism significantly affects tacrolimus pharmacokinetics in kidney transplant recipients. Clin Chem 57:1574-1583.

Gjestad C, Huynh DK, Haslemo T, and Molden E (2016) 4 $\beta$-hydroxycholesterol correlates with dose but not steady-state concentration of carbamazepine: indication of intestinal CYP3A in biomarker formation? Br J Clin Pharmacol 81:269-276.

Guévin C, Michaud J, Naud J, Leblond FA, and Pichette V (2002) Down-regulation of hepatic cytochrome p450 in chronic renal failure: role of uremic mediators. $\mathrm{Br} J$ Pharmacol 137 1039-1046.

Hole K, Gjestad C, Heitmann KM, Haslemo T, Molden E, and Bremer S (2017) Impact of genetic and nongenetic factors on interindividual variability in $4 \beta$-hydroxycholesterol concentration. Eur J Clin Pharmacol 73:317-324.

Hübner M, Mantziari S, Demartines N, Pralong F, Coti-Bertrand P, and Schäfer M (2016) Postoperative albumin drop is a marker for surgical stress and a predictor for clinical outcome: a pilot study. Gastroenterol Res Pract 2016:8743187.

Josephson F, Bertilsson L, Böttiger Y, Flamholc L, Gisslén M, Ormaasen V, Sönnerborg A, and Diczfalusy U (2008) CYP3A induction and inhibition by different antiretroviral regimen reflected by changes in plasma 4beta-hydroxycholesterol levels. Eur J Clin Pharmacol 64:775-781

Joy MS, Hogan SL, Thompson BD, Finn WF, and Nickeleit V (2007) Cytochrome P450 3A5 expression in the kidneys of patients with calcineurin inhibitor nephrotoxicity. Nephrol Dial Transplant 22:1963-1968.

Kirwan C, MacPhee I, and Philips B (2010) Using drug probes to monitor hepatic drug metabolism in critically ill patients: midazolam, a flawed but useful tool for clinical investigation of CYP3A activity? Expert Opin Drug Metab Toxicol 6:761-771.

Kirwan CJ, Lee T, Holt DW, Grounds RM, MacPhee IA, and Philips BJ (2009) Using midazolam to monitor changes in hepatic drug metabolism in critically ill patients. Intensive Care Med $\mathbf{3 5}$ $1271-1275$.

Kirwan CJ, MacPhee IA, Lee T, Holt DW, and Philips BJ (2012) Acute kidney injury reduces the hepatic metabolism of midazolam in critically ill patients. Intensive Care Med 38:76-84.

Kuehl P, Zhang J, Lin Y, Lamba J, Assem M, Schuetz J, Watkins PB, Daly A, Wrighton SA, Hall $\mathrm{SD}$, et al. (2001) Sequence diversity in CYP3A promoters and characterization of the genetic basis of polymorphic CYP3A5 expression. Nat Genet 27:383-391.

Ladda MA and Goralski KB (2016) The effects of CKD on cytochrome P450-mediated drug metabolism. Adv Chronic Kidney Dis 23:67-75.

Lütjohann D, Marinova M, Schneider B, Oldenburg J, von Bergmann K, Bieber T, Björkhem I, and Diczfalusy U (2009) 4beta-hydroxycholesterol as a marker of CYP3A4 inhibition in vivo effects of itraconazole in man. Int J Clin Pharmacol Ther 47:709-715.

Mangold JB, Wu F, and Rebello S (2016) Compelling relationship of CYP3A induction to levels of the putative biomarker 4beta-hydroxycholesterol and changes in midazolam exposure. Clin Pharmacol Drug Dev 5:245-249.

Marschall HU, Wagner M, Zollner G, Fickert P, Diczfalusy U, Gumhold J, Silbert D, Fuchsbichle A, Benthin L, Grundström R, et al. (2005) Complementary stimulation of hepatobiliary transport and detoxification systems by rifampicin and ursodeoxycholic acid in humans. Gastroenterology 129:476-485.
Matoulková P, Pávek P, Malý J, and Vlček J (2014) Cytochrome P450 enzyme regulation by glucocorticoids and consequences in terms of drug interaction. Expert Opin Drug Metab Toxicol 10:425-435.

Meijers BK, Bammens B, Verbeke K, and Evenepoel P (2008) A review of albumin binding in CKD. Am J Kidney Dis 51:839-850.

Michaud J, Dubé P, Naud J, Leblond FA, Desbiens K, Bonnardeaux A, and Pichette V (2005) Effects of serum from patients with chronic renal failure on rat hepatic cytochrome $\mathrm{P} 450 . \mathrm{Br} \mathrm{J}$ Pharmacol 144:1067-1077.

Morgan ET (1997) Regulation of cytochromes P450 during inflammation and infection. Drug Metab Rev 29:1129-1188.

Ngaimisi E, Minzi O, Mugusi S, Sasi P, Riedel KD, Suda A, Ueda N, Bakari M, Janabi M, Mugusi F, et al. (2014) Pharmacokinetic and pharmacogenomic modelling of the CYP3A activity marker $4 \beta$-hydroxycholesterol during efavirenz treatment and efavirenz/rifampicin co-treatment. $J$ Antimicrob Chemother 69:3311-3319.

Nolin TD, Appiah K, Kendrick SA, Le P, McMonagle E, and Himmelfarb J (2006) Hemodialysis acutely improves hepatic CYP3A4 metabolic activity. J Am Soc Nephrol 17:2363-2367.

Størset E, Åsberg A, Skauby M, Neely M, Bergan S, Bremer S, and Midtvedt K (2015) Improved tacrolimus target concentration achievement using computerized dosing in renal transplant recipients-a prospective, randomized study. Transplantation 99:2158-2166.

Størset E, Hole K, Midtvedt K, Bergan S, Molden E, and Åsberg A (2017) The CYP3A biomarker $4 \beta$-hydroxycholesterol does not improve tacrolimus dose predictions early after kidney transplantation. Br J Clin Pharmacol 83:1457-1465.

Størset E, Holford N, Midtvedt K, Bremer S, Bergan S, and Åsberg A (2014) Importance of hematocrit for a tacrolimus target concentration strategy. Eur J Clin Pharmacol 70:65-77.

Suzuki Y, Fujioka T, Sato F, Matsumoto K, Muraya N, Tanaka R, Sato Y, Ohno K, Mimata H, Kishino S, et al. (2015) CYP3A5 polymorphism affects the increase in CYP3A activity after living kidney transplantation in patients with end stage renal disease. $\mathrm{Br}$ J Clin Pharmacol 80: $1421-1428$.

Suzuki Y, Itoh H, Fujioka T, Sato F, Kawasaki K, Sato Y, Sato Y, Ohno K, Mimata H, and Kishino $S$ (2014) Association of plasma concentration of 4 $\beta$-hydroxycholesterol with CYP3A5 polymorphism and plasma concentration of indoxyl sulfate in stable kidney transplant recipients Drug Metab Dispos 42:105-110.

Suzuki Y, Itoh H, Sato F, Kawasaki K, Sato Y, Fujioka T, Sato Y, Ohno K, Mimata H, and Kishino $S$ (2013) Significant increase in plasma $4 \beta$-hydroxycholesterol concentration in patients after kidney transplantation. J Lipid Res 54:2568-2572.

Tomalik-Scharte D, Lütjohann D, Doroshyenko O, Frank D, Jetter A, and Fuhr U (2009) Plasma 4beta-hydroxycholesterol: an endogenous CYP3A metric? Clin Pharmacol Ther 86:147-153.

Wang D, Guo Y, Wrighton SA, Cooke GE, and Sadee W (2011) Intronic polymorphism in CYP3A4 affects hepatic expression and response to statin drugs. Pharmacogenomics $J \mathbf{1 1}$ 274-286.

Wide K, Larsson H, Bertilsson L, and Diczfalusy U (2008) Time course of the increase in 4betahydroxycholesterol concentration during carbamazepine treatment of paediatric patients with epilepsy. Br J Clin Pharmacol 65:708-715.

Zanger UM and Schwab M (2013) Cytochrome P450 enzymes in drug metabolism: regulation of gene expression, enzyme activities, and impact of genetic variation. Pharmacol Ther 138: $103-141$.

Address correspondence to: Kristine Hole, Center for Psychopharmacology, Diakonhjemmet Hospital, PO Box 23 Vinderen, 0319 Oslo, Norway. E-mail: kristine. hole@diakonsyk.no 